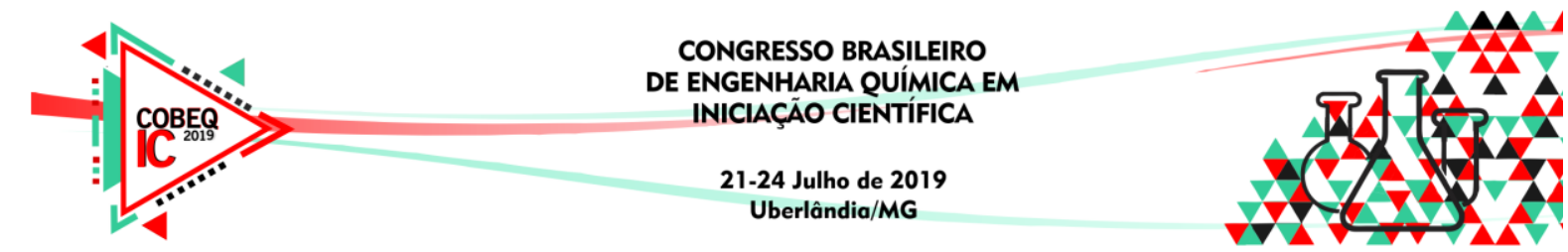

\title{
SECAGEM DE SOJA EM SECADOR ROTO-AERADO E AVALIAÇÃO DA QUALIDADE DA SEMENTE
}

\author{
F. R. C. FERREIRA ${ }^{1}$, J. H. C. L. MOREIRA ${ }^{1}$, M.C.C. FRANCISQUETTI ${ }^{1}$, G. F. M. V. \\ SOUZA $^{1}$, M. A. S. BARROZO ${ }^{1}$ \\ ${ }^{1}$ Universidade Federal de Uberlândia, Faculdade de Engenharia Química \\ E-mail para contato: fabianarcf5@gmail.com
}

\begin{abstract}
RESUMO - A soja é uma das principais culturas da economia agrícola do Brasil. A produção da semente com qualidade elevada tem sido um desafio para esse setor e técnicas especiais de produção devem ser adotadas, e dentre esses processos, a secagem possui grande relevância. Com isso, o objetivo do presente trabalho foi estudar a secagem das sementes de soja em secador roto-aerado, avaliando a influência da temperatura e da velocidade do ar de secagem na desidratação e os impactos na qualidade física e fisiológica dessas sementes. Observou-se resultados promissores, uma vez que o tempo médio de residência (entre 21 e 23,7 minutos) foi bastante reduzido em relação a outros secadores, sendo possível secar e manter bons índices de qualidade das sementes de soja nesse secador.
\end{abstract}

\section{INTRODUÇÃO}

A soja, Glycine max L., com uma cultura originária da China, é uma leguminosa que chama a atenção pelo seu valor nutricional, sendo rica em proteínas $(45 \%)$ e óleo (20\%), ela pode ser destinada tanto para alimentação humana quanto para a alimentação animal, além de ser também utilizada para a produção de biodisel, um biocombustível obtido pela reação de transesterificação a partir da extração de seu óleo (Silva et al., 2016).

O Brasil se tornou um dos maiores produtores mundiais de soja, devido aos avanços para novas regiões agrícolas, principalmente o Cerrado, ao aumento crescente da área de produção e aos constantes aumentos de produtividade. A semente teve um papel fundamental na construção deste panorama, sendo que ela passou a ser o produto de maior área plantada devido aos constantes avanços tecnológicos, a sua crescente produção e demanda crescente do mercado (Carraro, 2006).

A produção de sementes de soja depende também de uma infraestrutura adequada disponível no momento da colheita e no beneficiamento, como, por exemplo, um número adequado de máquinas colhedoras e o uso de condições adequadas para a secagem das sementes (França Neto et al., 2007).

A secagem é um processo fundamental, pois auxilia na obtenção de um produto com qualidade e umidade adequadas para comercialização, além de favorecer a conservação por um tempo mais prolongado. Segundo Athié et al. (1998), um processo de secagem eficiente é aquele que, além de reduzir o teor de água do produto, aumenta seu potencial de conservação 


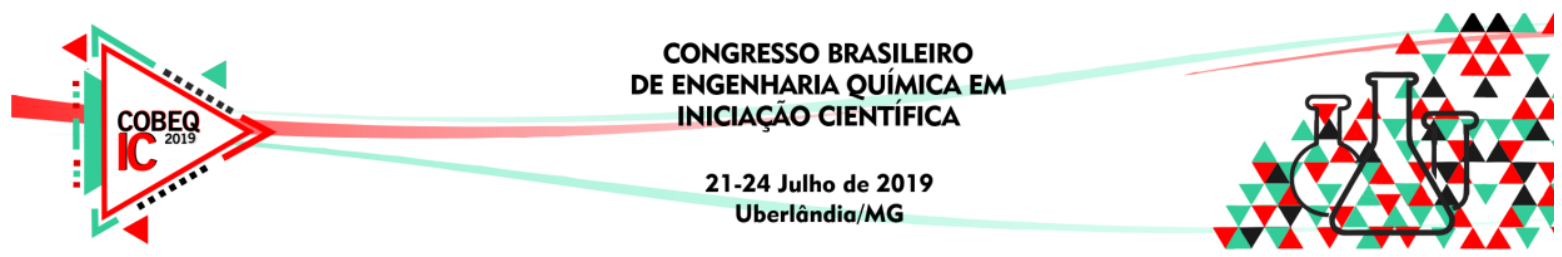

pós-colheita e preserva suas características físicas e propriedades tecnológicas, atribuindo-lhe alto valor comercial. A obtenção de sementes de alta qualidade está diretamente relacionada com a forma com que ocorre a secagem. Sendo assim, a escolha do método de secagem e do secador é de grande importância (Guimarães, 2005). Nesse sentido, devido à elevada capacidade de processamento, os secadores rotatórios se mostram como uma alternativa para a secagem de sementes de soja.

Dentro do exposto, este trabalho objetivou avaliar a secagem das sementes de soja em secador roto-aerado, para verificar a influência da temperatura e da velocidade do ar de secagem no teor de umidade e na qualidade física e fisiológica dessas sementes.

\section{MATERIAIS E MÉTODOS}

\subsection{Material utilizado}

Foram utilizadas sementes comerciais de soja geneticamente modificadas para os procedimentos experimentais, adquiridas no mercado formal. Essas sementes utilizadas nos experimentos foram reumidificadas artificialmente por meio da absorção do vapor de água saturado pela semente até atingirem a umidade inicial desejada. Elas foram colocadas em bandejas dentro de uma câmara com água a uma temperatura controlada $\left(40^{\circ} \mathrm{C}\right)$, onde não havia contato direto das sementes com a água. Após cada reumidificação para a realização dos experimentos, a qualidade das sementes foi novamente mensurada. Verificou-se que a qualidade das sementes praticamente se manteve, o que indica que esse processo foi adequado. As sementes apresentavam-se com cerca de $94 \%$ sem fissura e $92 \%$ de germinação.

\subsection{Aparato experimental}

A secagem foi realizada em uma nova versão do secador rotatório desenvolvida no Laboratório de Sistemas Particulados (LSP) da Faculdade de Engenharia Química da Universidade Federal de Uberlândia (UFU), e denominada de secador roto-aerado, representado na Figura 1.

Figura 1 - Unidade experimental para a secagem das sementes em secador roto-aerado.

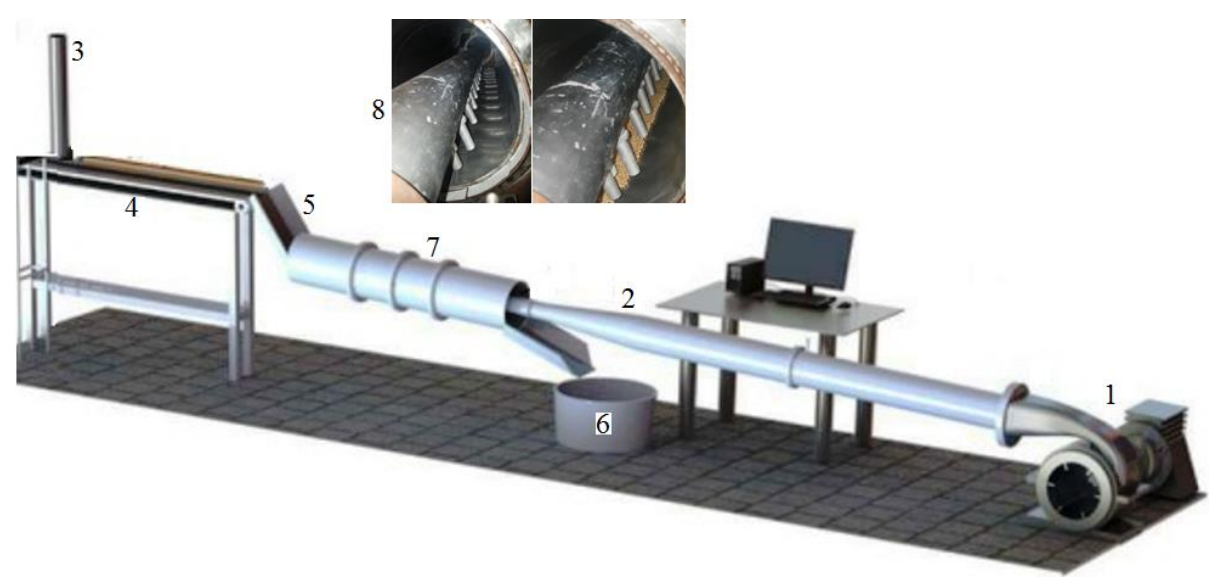




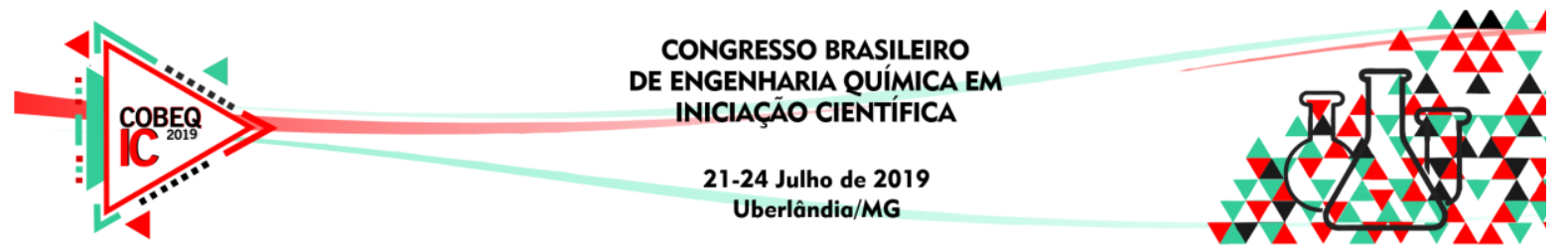

A unidade experimental era constituída basicamente por um soprador do tipo ventilador radial (1) acoplado a um duto com comprimento de $2 \mathrm{~m}$ e $0,2 \mathrm{~m}$ de diâmetro. Entre esse duto e o secador existia um sistema de aquecimento com resistências elétricas (2), controladas por dois variadores de voltagem. Esse sistema permitia a variação da tensão e consequentemente da corrente elétrica que, por fim, implicavam em alterações do calor fornecido ao ar. As sementes de soja úmidas foram armazenadas num reservatório (3) montado em cima de uma correia transportadora (4) responsável pelo carregamento dos sólidos. As sementes úmidas escoavam até entrada do secador por uma calha (5). As sementes eram removidas na outra extremidade do secador, e o material era direcionado para um reservatório (6) por meio de uma segunda calha. $\mathrm{O}$ tambor rotatório (7) possuía a superfície interna coberta por chapas de aço inoxidável de $0,5 \mathrm{~mm}$ de espessura, com comprimento de $1,5 \mathrm{~m} \mathrm{e} 0,29 \mathrm{~m}$ de diâmetro (relação $\mathrm{L} / \mathrm{D}=5$ ), sendo que a estrutura permitia variações de inclinação e rotação. A configuração do secador roto-aerado possuía 56 minitubos (8) com diâmetros de 0,012 m e 0,095 m de comprimento, os quais direcionam o ar para as sementes úmidas.

\subsection{Planejamento experimental}

A secagem das sementes de soja foi realizada no secador roto-aerado com as seguintes configurações: inclinação de $0,2^{\circ}$; rotação do tambor de $1,5 \mathrm{rpm}$; vazão de alimentação de $0,06 \mathrm{~kg} \mathrm{~min}^{-1}$. Estas condições foram fixadas de acordo com os resultados obtidos em testes preliminares, para garantir um melhor escoamento do material dentro do secador.

Para constatar a influência das variáveis temperatura $(\mathrm{T})$ e a velocidade (v) do ar de secagem, na umidade e na qualidade das sementes, foram realizados 12 experimentos, para os quais os valores utilizados para cada variável estão apresentados no planejamento experimental e descritos na Tabela 1.

Tabela 1 - Planejamento experimental

\begin{tabular}{|c|c|c|}
\hline Exp. & $\begin{array}{c}\mathrm{T} \\
\left({ }^{\circ} \mathrm{C}\right)\end{array}$ & $\begin{array}{c}\mathrm{v} \\
\left(\mathrm{m} \cdot \mathrm{s}^{-1}\right)\end{array}$ \\
\hline 1 & 30 & 0,9 \\
\hline 2 & 35 & 0,9 \\
\hline 3 & 40 & 0,9 \\
\hline 4 & 45 & 1,5 \\
\hline 5 & 48 & 1,1 \\
\hline 6 & 48 & 1,9 \\
\hline 7 & 55 & 0,9 \\
\hline 8 & 55 & 1,5 \\
\hline 9 & 55 & 2,1 \\
\hline 10 & 62 & 1,1 \\
\hline 11 & 62 & 1,9 \\
\hline 12 & 65 & 1,5 \\
\hline
\end{tabular}




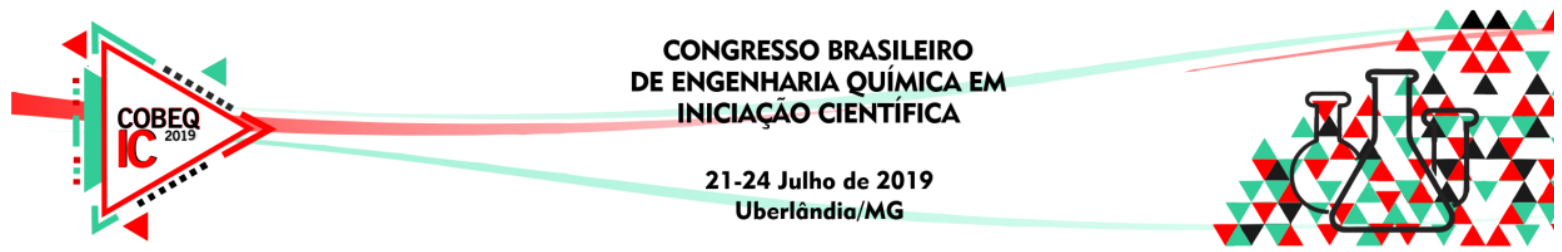

Para os testes de secagem, ligava-se o soprador, o sistema de aquecimento e a rotação do tambor nas condições operacionais estabelecidas pelo planejamento experimental. O sistema permaneceu nessas condições, ainda sem alimentação do resíduo, até que a temperatura e a velocidade do ar estabilizassem. Em seguida, as sementes foram alimentadas no secador. Após certificar que o sistema está em regime permanente recolhem-se as amostras para análises de umidade, temperatura, fissura e germinação. Deve-se ressaltar que todos os experimentos de secagem, em secador roto-aerado, foram realizados em uma faixa 40 a $60 \%$ de umidade relativa do ar.

A velocidade de entrada do ar de secagem foi medida por um anemômetro de fio quente. A vazão mássica de sólidos foi ajustada pela coleta periódica de amostra na entrada do secador e pesagem em balança analítica. As temperaturas do ar, na entrada e na saída do secador, foram medidas utilizando-se termopares de cobre-constantan, previamente calibrados.

\subsection{Análises realizadas}

Ao final de cada experimento foi aferida a umidade final (Uf) em base úmida (bu) pelo método da estufa (105 $\pm 2{ }^{\circ} \mathrm{C}$ por 24 horas) para cálculo da taxa de secagem (em pontos percentuais por minuto - pp $\mathrm{min}^{-1}$ ), e o tempo de residência $(\tau)$. Foram também realizados os testes para determinação da qualidade das sementes (fissura e germinação). As medidas do tempo médio de residência foram realizadas pesando a carga de sólidos do secador em balança analítica e dividindo pela vazão de sólidos alimentados. O cálculo da taxa de secagem foi feito considerando a diferença entre a umidade inicial e a final em relação ao tempo de residência de cada corrida experimental. Para a qualidade das sementes, antes e depois da secagem, foi avaliada a porcentagem de sementes sem fissuras no tegumento pelo teste do hipoclorito de sódio, e a porcentagem de germinação das sementes.

Teste do hipoclorito de sódio: Para este teste as sementes foram colocadas em recipientes e cobertas com solução hipoclorito de sódio a 5\%. Foram utilizadas duas repetições de 100 sementes para cada análise. Decorridos 10 minutos, a solução foi escorrida e as sementes distribuídas sobre folhas de papel toalha, sendo contado o número de sementes intumescidas. As sementes intumescidas são aquelas que apresentam fissuras ou microfissuras no tegumento. Os resultados foram expressos em percentagem média por amostra (Krzyzanowski et al., 2004). Os valores obtidos em cada um dos experimentos foram divididos pelos respectivos valores da amostra retirada após a reumidificação obtendo-se assim o índice de sementes sem fissuras (ISSF).

Teste de germinação: $O$ teste de germinação foi realizado utilizando-se 200 sementes para cada experimento, conforme metodologia prescrita pelas Regras de Análise de Sementes - RAS (Brasil, 2009). Foi utilizado o substrato de rolo de papel umedecido com água deionizada. Após montagem dos rolos estes foram colocados em germinadores com temperatura de $25 \pm 1{ }^{\circ} \mathrm{C}$. As avaliações foram feitas aos cinco dias após o início do teste, determinando-se a porcentagem de plântulas normais, que corresponde a porcentagem de germinação. Os valores obtidos em cada um dos experimentos foram divididos pelos respectivos valores da amostra retirada após a reumidificação obtendo-se assim o índice de germinação (IG) das sementes. 


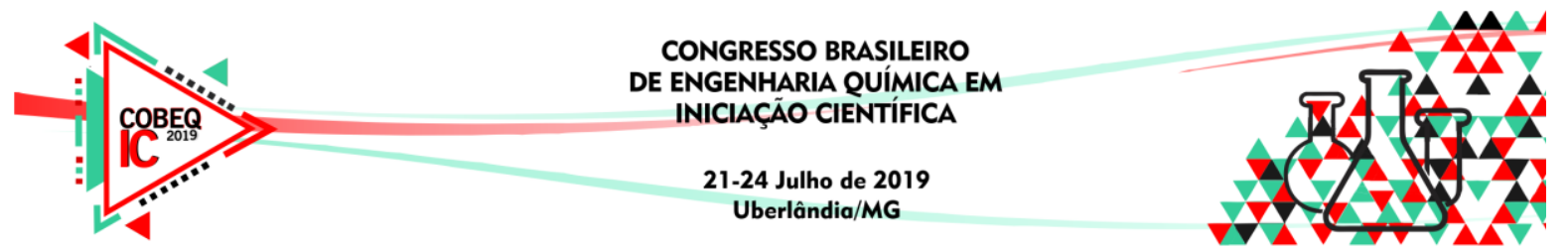

\section{RESULTADOS E DISCUSSÕES}

A umidade inicial das sementes apresentou valores de 14,9 $\pm 0,2 \%$ (bu). A Tabela 2 apresenta a umidade final $\left(\mathrm{U}_{\mathrm{f}}\right)$, o tempo de residência $(\tau)$, a taxa de secagem (Taxa), e a qualidade das sementes (ISSF e IG) após o processo de secagem em secador roto-aerado. A taxa de secagem variou de 0,030 pp $\min ^{-1}$ (Exp. 1) a 0,095 pp $\min ^{-1}$ (Exp. 12). A umidade final do material após as secagens ficou entre 12,8 a 14,5\% (bu).

Tabela 2 - Resultados para as secagens das sementes de soja em secador roto-aerado

\begin{tabular}{|c|c|c|c|c|c|c|c|}
\hline Exp. & $\begin{array}{c}\mathrm{T} \\
\left({ }^{\circ} \mathrm{C}\right)\end{array}$ & $\begin{array}{c}\mathrm{v} \\
\left(\mathrm{m} \mathrm{s}^{-1}\right)\end{array}$ & $\begin{array}{c}\mathrm{U}_{\mathrm{f}} \\
(\% \mathrm{bu})\end{array}$ & $\begin{array}{c}\tau \\
(\mathrm{min})\end{array}$ & $\begin{array}{c}\text { Taxa } \\
\left(\mathrm{pp} \mathrm{min}^{-1}\right)\end{array}$ & $\begin{array}{c}\text { ISSF } \\
(\%)\end{array}$ & $\begin{array}{c}\text { IG } \\
(\%)\end{array}$ \\
\hline 1 & 30 & 0,9 & 14,5 & 23,3 & 0,030 & 93 & 89 \\
\hline 2 & 35 & 0,9 & 14,3 & 23,7 & 0,034 & 92 & 87 \\
\hline 3 & 40 & 0,9 & 14,2 & 23,0 & 0,039 & 90 & 86 \\
\hline 4 & 45 & 1,5 & 14,0 & 22,5 & 0,044 & 43 & 85 \\
\hline 5 & 48 & 1,1 & 13,5 & 22,7 & 0,053 & 50 & 85 \\
\hline 6 & 48 & 1,9 & 13,3 & 22,2 & 0,063 & 40 & 82 \\
\hline 7 & 55 & 0,9 & 13,6 & 22,3 & 0,058 & 34 & 79 \\
\hline 8 & 55 & 1,5 & 13,2 & 22,0 & 0,068 & 25 & 77 \\
\hline 9 & 55 & 2,1 & 13,2 & 22,2 & 0,072 & 21 & 73 \\
\hline 10 & 62 & 1,1 & 13,1 & 22,3 & 0,076 & 26 & 73 \\
\hline 11 & 62 & 1,9 & 13,0 & 22,5 & 0,080 & 17 & 66 \\
\hline 12 & 65 & 1,5 & 12,8 & 21,0 & 0,095 & 16 & 65 \\
\hline
\end{tabular}

O tempo médio de residência do material no secador variou de 21,0 min (Exp. 12) a 23,7 min (Exp. 2), que são valores baixos quando comparados com a secagem em leito fixo, geralmente o mais utilizado para secagem de sementes de soja, que pode requer tempos acima de 3 horas de secagem (Souza, 2013). O reduzido tempo necessário para a secagem em secador roto-aerado se deve ao maior contato fluido-partícula (Silvério et al., 2015).

É importante frisar que umidade final na maioria dos experimentos ficou fora do valor preconizado para um armazenamento seguro das sementes, que seria entre 12 e $13 \%$ (bu). Em apenas dois experimentos $(11 \mathrm{e} 12)$ as sementes obtiveram a umidade final no intervalo considerado adequado. Esses valores foram obtidos nas temperaturas mais elevadas (62 e 65 $\left.{ }^{\circ} \mathrm{C}\right)$ e em maiores velocidades do ar $\left(1,9\right.$ e $\left.1,5 \mathrm{~m} \mathrm{~s}^{-1}\right)$, onde também se observa maiores taxas de secagem $\left(0,080\right.$ e 0,095 pp $\left.\mathrm{min}^{-1}\right)$, ou seja, maiores reduções da umidade da semente.

Contudo, nos resultados em que a umidade final é adequada, a qualidade da semente (índice de fissura e germinação) obteve valores baixos. $O$ índice de sementes sem fissuras (ISSF), foi o mais afetado, com resultados altos, como $93 \%$ em baixa temperatura e velocidade, e baixos, abaixo de $50 \%$ em altas temperaturas e velocidade do ar de secagem. O índice de germinação (IG) obteve valores altos, alguns acima de $80 \%$, mas também houve resultados mais baixos, como 66 e $65 \%$, observando as mesmas influências que a temperatura e a velocidade exerceram sobre o ISSF no IG. 


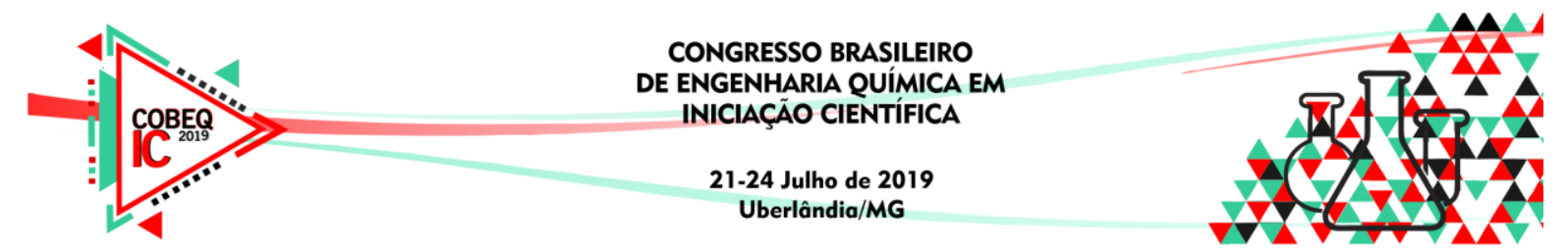

Com esses resultados, pode-se observar que com altos valores de velocidade e temperatura do ar de secagem, a qualidade das sementes não foi a mais adequada, mas a umidade final e a taxa de secagem tiveram resultados satisfatórios. E com a diminuição das variáveis, a qualidade alcançou valores altos.

\section{CONCLUSÃO}

Analisando as secagens realizadas pelo secador roto-aerado os resultados demonstraram uma configuração promissora, pois a secagem apresentou um tempo médio de residência bastante reduzido quando comparado com outros secadores, como o leito fixo. É possível secar sementes de soja e propiciar a manutenção da qualidade física e fisiológica dessas sementes no secador roto-aerado, entretanto ainda são necessários novos estudos para se ajustar as condições experimentais para que se consiga também diminuir a umidade dessas sementes a valores ideais, entre 12 e $13 \%$ (bu).

\section{REFERÊNCIAS}

ATHIÉ, I.; CASTRO, M.F.P.M.; GOMES, R. A. R.; VALENTINI, S. R. T. Conservação de grãos. Campinas: Fundação Cargill, 1998. 236p.

BRASIL. Ministério da Agricultura, Pecuária e Abastecimento - MAPA. Regras para análise de sementes, Brasília, Mapa/ACS. 2009.

CARRARO, I. M. Soja geneticamente modificada tolerante a herbicidas, Londrina, Anais do IV Congresso Brasileiro de Soja, vol. 1, p. 140-143, Embrapa Soja, Londrina - PR, 2006.

FRANÇA NETO, J. B.; KRZYZANOWSKI, F. C.; PÁDUA, G. P.; COSTA, N. P.; HENNING, A. A. Tecnologia da produção de sementes de soja de alta qualidade, Embrapa Soja, Londrina - PR, 2007.

GUIMARÃES, D. S. Desenvolvimento de módulo computacional para a secagem estacionária de sementes. PPG-FAEM/UFPEL - Pelotas, RS, 155p. 2005. (Tese de Doutorado).

KRZYZANOWSKI, F. C.; FRANÇA NETO, J. B.; COSTA, N. P. Teste do hipoclorito de sódio para semente de soja, Embrapa Soja, Londrina - PR, 2004.

SILVA, A. C.; LIMA, E. P. C.; BATISTA, H. R. A importância da soja para o agronegócio brasileiro: uma análise sob o enfoque da produção, emprego e exportação, $\mathrm{X}$ Encontro de Economia Catarinense, Blumenau-SC, 2016.

SILVERIO, B. C.; ARRUDA, E. B.; DUARTE, C. R.; BARROZO, M. A. S. A novel rotary dryer for drying fertilizer: Comparison of performance with conventional configurations. Powder Technol., v. 270, p.135-140, 2015.

SOUZA, G. F. M. V. Secagem de sementes de soja em leito fixo: equilíbrio e cinética da sílica gel para controle de umidade, modelagem do processo e análise da qualidade das sementes. PPGFEMEC/UFU - Campus Santa Mônica, Uberlândia - MG, 157f. 2013. (Tese de Doutorado) 